\title{
Marginal discrepancy and microleakage in crown-copings fabricated by three CAD/CAM systems: An in vitro study
}

\author{
Marcela Herrera ${ }^{1}$, Alfonso Catalán ${ }^{1 *}$, Maritza Flores ${ }^{2}$, Alejandra Martínez ${ }^{3}$ \\ ${ }^{1}$ Department of Restorative Dentistry, Faculty of Dentistry, University of Concepción, Concepción, Chile \\ ${ }^{2}$ Department of Public Health, School of Medicine, University of Concepción, Concepción, Chile \\ ${ }^{3}$ Department of Oral Pathology, Faculty of Dentistry, University of Concepción, Concepción, Chile \\ Email: ${ }^{*}$ acatalan@udec.cl
}

Received 23 March 2012; revised 13 April 2012; accepted 19 May 2012

\section{ABSTRACT}

The purpose of this study was to evaluate and compare the microleakage and marginal discrepancy of ceramic crown-copings fabricated by three different CAD/CAM systems. Material and methods: Thirty extracted premolars were prepared for complete allceramic crowns with: total convergence 10-degree, 2 mm occlusal reduction, $4.5 \mathrm{~mm}$ height, $1.3 \mathrm{~mm}$ circular reduction and chamfer marginal preparation. They were divided into three groups and each group $(n=10)$ received a ceramic crown-coping fabricated by one of three CAD/CAM systems: Procera, KaVo Everest and Cerec inLab. The copings were cemented with Panavia F 2.0. After thermal cycling, the teeth were immersed in $\mathbf{2} \%$ basic fuchsine dye for 24 hours. Microleakage was scored using a five-point scale and evaluated under a stereomicroscope at $\times 18$. Marginal discrepancies were assessed with scanning electronic microscope at $\times 150$, with measurements at 50 different points. Data were subjected to a chi-square test, Kolmogorov-Smirnov test and using Rho Spearman's correlation test $(P<0.05)$. Results: Cerec inLab CAD/CAM crown-copings showed significant microleakage compared to Procera and KaVo Everest $(P=$ 0.031). No significant differences were observed between Procera and the KaVo Everest system $(P>$ 0.05). No significant differences were found in marginal discrepancies for the Procera $(62.58 \pm 8.98 \mu \mathrm{m})$ and KaVo Everest systems (65.54 $\pm 18.56 \mu \mathrm{m}),(P=$ 0.941). Significant differences were found for Cerec inLab $(132.18 \pm 27.75 \mu \mathrm{m})$ compared with Procera and KaVo Everest $(P=\mathbf{0 . 0 0 0 1})$. No correlation between the marginal discrepancies and microleakage for the three CAD/CAM crown-copings systems. Conclusions: Cerec inLab CAD/CAM crown-copings showed significantly higher values for microleakage and marginal discrepancy in comparison with Pro-

${ }^{*}$ Corresponding author. cera and KaVo Everest CAD/CAM crown-copings.

Keywords: CAD/CAM Copings; Microleakage;

Marginal Discrepancy; Panavia F.2

\section{INTRODUCTION}

All-ceramic crowns fabricated by computer-aided design/ computer assisted manufacturing (CAD/CAM) technology are increasingly demanded by patients and clinicians due to superior esthetics, durability, biocompatibility and many improved physical properties in comparison with existing all-ceramic systems [1-5]. Microleakage permits the percolation of food, oral debris and others substances that can produce caries and periodontal disease [6]. Indeed, several studies have reported that microleakage is a complex interaction between many variables such as luting agent, cement shrinkage on setting, marginal gaps, tooth tissues, and differences in the luting material's coefficient of thermal expansion with tooth restorations [7-12]. Marginal discrepancy and microleakage are important causes of dental crown failure $[13,14]$.

The marginal discrepancy for different all-ceramic crowns has been studied in vitro and in vivo [2,3,5,10-12, 15-22] and the results show high variation between the different crown systems. The values ranged from $17.18 \pm 8.16$ to $145 \mu \mathrm{m}[2,3,5,17,19,22]$. Microleakage can be related to marginal discrepancy, although no strong correlation between marginal discrepancy and microleakage has been reported for all ceramic crowns $[8,11]$.

The review of the literature revealed a limited number of studies that had investigated the correlation between the marginal discrepancy and microleakage in ceramic copings fabricated by $\mathrm{CAD} / \mathrm{CAM}$ systems. Thus, the purpose of this in vitro study was to evaluate and compare the microleakage and marginal discrepancy of ceramic crown-copings generated by three different $\mathrm{CAD} /$ CAM systems. Two research hypotheses were stated to evaluate marginal discrepancy and microleakage: 1) There is no significant difference between the mean val- 
ues of marginal discrepancy and microleakage for each of the three CAD/CAM systems; and 2) there is no correlation between marginal discrepancy and microleakage.

\section{MATERIAL AND METHODS}

Thirty extracted non-carious premolars of similar size were selected. All teeth were stored in $0.1 \%$ thymol solution at room temperature. Calculus and residual periodontal tissue were removed using a surgical knife, scaler, and curette. Teeth were then divided into three groups of 10 teeth each; each group received a different crowncopings, fabricated by the following CAD/CAM systems: Procera (Nobel Biocare AB, Goteborg, Sweden/Mahwah, NJ), KaVo Everest system (KaVo Dental Corp, Lake Zurich, Switzerland) and Cerec inLab (Sirona Dental System Ltd., Bensheim, Germany).

Teeth were prepared for complete all ceramic crowns by a single clinician. The teeth were prepared with a total convergence of 10 degrees, an occlusal reduction of 2 $\mathrm{mm}$, height of approximately $4.5 \mathrm{~mm}$, followed by a circular reduction of $1.3 \mathrm{~mm}$. The cervical preparation margins were designed as circular chamfers using torpedoshaped diamond burs and water FG (Coltène/Whaledent AG, Alstatten, Switzerland).

Once the dental pieces were prepared, the teeth were mounted in a Type IV ResinRock plaster base (WhipMix, Louisville, Ky) with the main teeth axis oriented perpendicularly to the pedestal surface to simulate an arch, and thus facilitating the creation of an individual tray and impression. A full arch impression was made with silicone by adding Elite H-D + Putty Soft Normal Setting and Elite H-D + Light Body Normal Setting (Zhermack, Badia Polesine, Italy). Three working models were made in resin in order to make high precision Exakto-Form models with a polyurethane base (Bredent, Senden, Germany). The scanner data was then sent for coping fabrication by the following CAD/CAM systems: Procera (Nobel Biocare AB), KaVo Everest system (KaVo Dental Corp) and Cerec inLab (Sirona Dental System Ltd.). Highly specialized personnel fabricated the copings.

For the Procera system, the die was digitized by scanning Procera Font (Nobel Biocare Ltd. Mahwah, USA). Tooth preparation data was electronically transmitted to the laboratory (Procera, USA) where the sintered aluminous oxide coping of $0.6 \mathrm{~mm}$ thick was fabricated. The KaVo Everest system die was digitalized with light beam projection and the information was then sent to a cutter to mold a pre-sinterized zircon oxide block (ZS-Blank, Everest). The copings were defined with a standard cut, with a marginal discrepancy of $0.03 \mathrm{~mm}$, rapid occlusion, spacing for cement of $0.1 \mathrm{~mm}$, offset form of $0.5 \mathrm{~mm}$, and cervical border thickness of $0.3 \mathrm{~mm}$, and were then sinterized in a KaVo Everest Term oven. The Cerec inLab system uses pre-sinterized aluminum oxide blocks
VITA In-CeramAL 20, which were milled in the inLab apparatus (Sirona Dental Systems GMBH, Bensheim, Germany), using the die laser reader. After imaging, the data was processed. Coping fabrication was defined with a circular thickness at the cervical border level of $0.6 \mathrm{~mm}$ and occlusal thickness of $1 \mathrm{~mm}$.

After bonding the intaglio surface of the ceramiccopings, the airborne particle was abraded with $50 \mu \mathrm{m}$ alumina powder at two bars of pressure for 3 - 5 seconds.

Each coping was cemented with dual-cured resin cement Panavia F 2.0 (Kuraray Medical Inc, Tokyo, Japan) according to the manufacturer's recommendations. The dental surface was treated with the application of the self-sealing ED Primer II (Panavia F 2.0) to the entire adherent tooth surface for 30 seconds using a disposable point. The cement was prepared by mixing equal portions of both pastes for 20 seconds. To bond, the Panavia was loaded onto the coping's interior surface and finger pressure was applied, followed by the application of 5 $\mathrm{Kg}$ standardized load for ten minutes [10]. The cement was polymerized for 20 seconds using light-curing unit LEDs Smartlite ${ }^{\mathrm{TM}}$ PS (Densply, De Trey GMBH, Konstanz, Germany), with an approximate output of 950 $\mathrm{mWcm}^{2}$. The distance between the light tip and the specimens was $10 \mathrm{~mm}$. Excess cement was removed with a probe.

Immediately after cementing the copings, the specimens were stored at $37^{\circ} \mathrm{C}$ temperature and $100 \%$ humidity in an incubator for 24 hours. Subsequently, they were thermocycled in water bath of $5^{\circ} \mathrm{C}$ and $55^{\circ} \mathrm{C}$ (Model Haake C-10 W 15, Thermo; Karlsruhe, Germany) for 500 cycles [23], to simulate oral conditions. The immersion time was 40 seconds with 3 seconds of transfer time [12].

After thermal cycling, root apices were sealed with composite resin Z100 (3M ESPE AG, Seefeld, Germany), and the surfaces apical to the margins were covered with two layers of nail varnish down to $1 \mathrm{~mm}$ below the coping margins $[8,12]$. Afterwards, the teeth were immersed in $2 \%$ basic fuchsine dye solution for 24 hours at room temperature [10]. The specimens were rinsed thoroughly in water, and sectioned mesiodistally only one time, obtaining two halves using a diamond disc and water spray. Each section side was examined under stereomicroscope (model Stemi SV6, ZEISS, Jena, Germany) at $\times 18$ magnification. Photographs were taken with a camera (DXM 1200F Nikon, Tokyo, Japan) using the imaging program Nikon ACT-1 V.2.63 (Nikon, Tokyo, Japan). The images were taken with resolution $350 \mathrm{dpi}$, TIFF, size 1000 and bar $2 \mathrm{~mm}$.

Microleakage was rated according to the followings score:

$$
\begin{aligned}
& 0=\text { no leakage. } \\
& 1=\text { leakage up to one third of dentin. } \\
& 2=\text { leakage up to two thirds of dentin. } \\
& 3=\text { leakage up to three thirds of dentin without com- }
\end{aligned}
$$


promise of pulp.

4 = leakage up to three thirds of dentin with compromise of pulp.

All marginal discrepancies were measured after evaluating microleakage. Marginal discrepancy was assessed with a scanning electron microscope (SEM) (JEOL, Tokyo, Japan) at $\times 150$ magnification and the angulation was zero according to Holmes et al. [15]. The teeth were sputtered with gold for 4 minutes. Then they were measured at 50 different points along the coping margins, according to Groten et al. who suggested that 50 measurements were the minimal amount acceptable to achieve a clinically relevant result [24]. In this study, the criterion of $120 \mu \mathrm{m}$ was used as the maximum clinically acceptable marginal opening following Mc Lean and Von Fraunhofer[16]. Data was analyzed with statistical software (SPSS, version 16.0; SPSS, Inc., Chicago, Ill). Differences between groups were examined using the chi-square test and Kolmogorov-Smirnov test. The association between variables was determined using Rho Spearman's correlation test. Differences were considered statistically significant when $P<0.05$.

\section{RESULTS}

As shown in the representative microphotographs (Figures 1-5), CAD/CAM ceramic crown-coping samples stained with $2 \%$ basic fuchsine solution presented the following types of microleakage: no leakage (in positive samples, 14/60), leakage up to one third of dentin (in positive samples, 28/60), leakage up to two-thirds of dentin (in positive samples, 2/60), leakage up to threethirds of dentin without pulp compromise (in positive samples, 2/60), and leakage up to three-thirds of dentin with pulp compromise (in positive samples (14/60). Table 1 summarizes the results of microleakage for Procera, KaVo Everest and Cerec inLab CAD/CAM crown-copings.

When comparing microleakage with $2 \%$ basic fuchsine solution, Cerec inLab CAD/CAM crown-copings presented the highest stain levels when compared with Procera and KaVo Everest $(P=0.031$, chi-square test), although there were no differences between Procera CAD/CAM crown-copings to KaVo Everest system $(P>$ 0.05 , chi-square test).

Table 2 shows the mean values, SD, and minimum and maximum of marginal discrepancies using the SEM for ceramic crown-copings fabricated by CAD/CAM systems Procera, KaVo Everest and Cerec inLab.

No significant differences $(P=0.941$, KolmogovSmirnov test) were found for marginal discrepancy when comparing Procera CAD/CAM crown-copings to KaVo Everest. Nevertheless, significant differences were found between the Procera and KaVo Everest systems for $\mathrm{CAD} / \mathrm{CAM}$ crown-copings when compared with Cerec

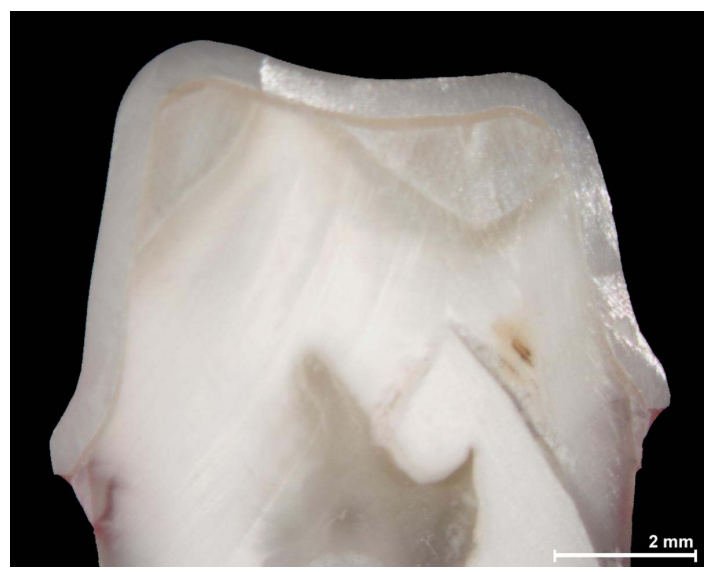

Figure 1. Representative microphotograph of microleakage detection with $2 \%$ fuchsine basic. As described in section "material and methods". The tooth section shows no leakage. Bar represents $2 \mathrm{~mm}$.

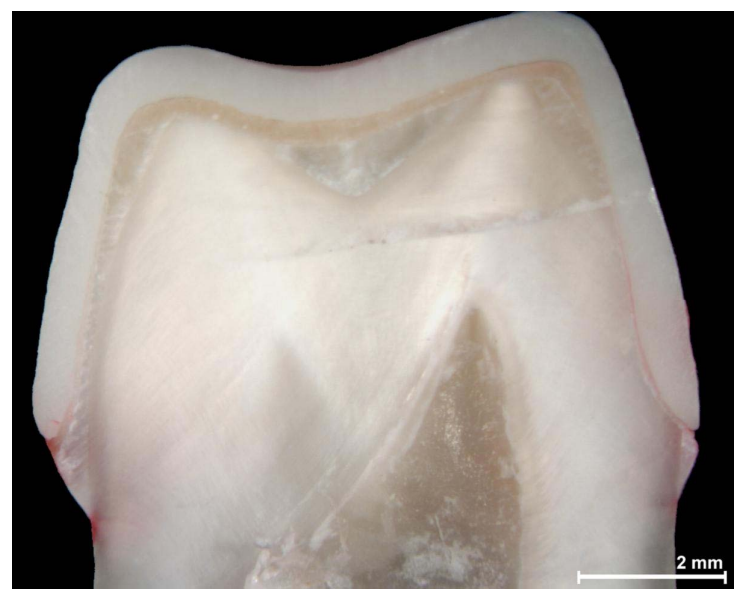

Figure 2. Representative microphotograph of microleakage detection with $2 \%$ fuchsine basic. As described in section "material and methods". The tooth section shows leakage up to one third of dentin. Bar represents $2 \mathrm{~mm}$.

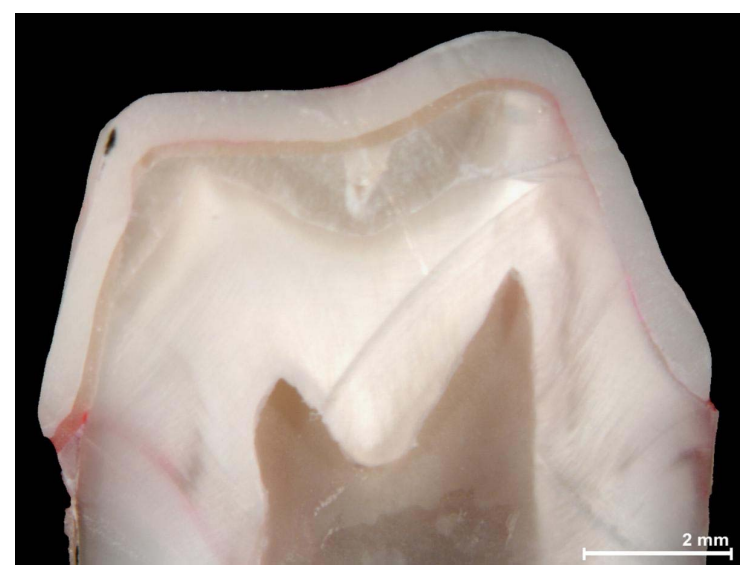

Figure 3. Representative microphotograph of microleakage detection with $2 \%$ fuchsine basic. As described in section "material and methods". The tooth section shows leakage up to two thirds of dentin. Bar represents $2 \mathrm{~mm}$. 


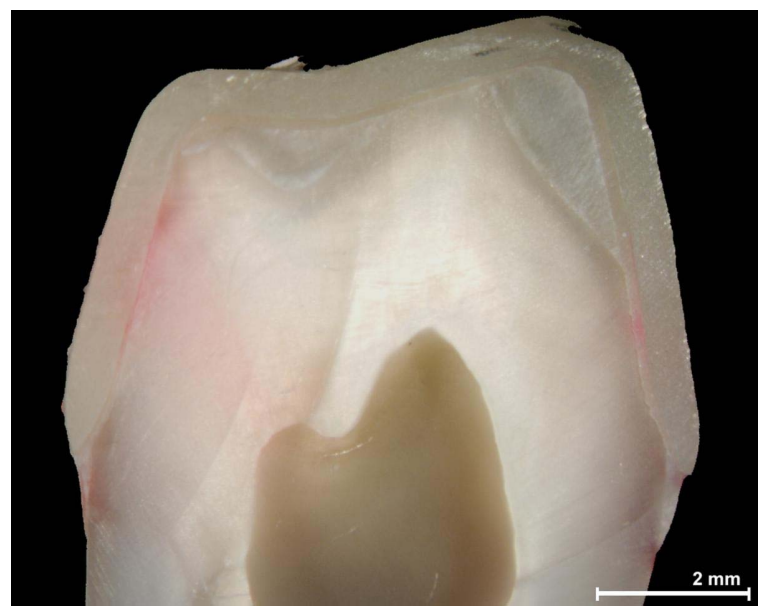

Figure 4. Representative microphotograph of microleakage detection with $2 \%$ fuchsine basic. As described in section "material and methods". The tooth section shows leakage up to three thirds of dentin without compromise of pulp. Bar represents $2 \mathrm{~mm}$.

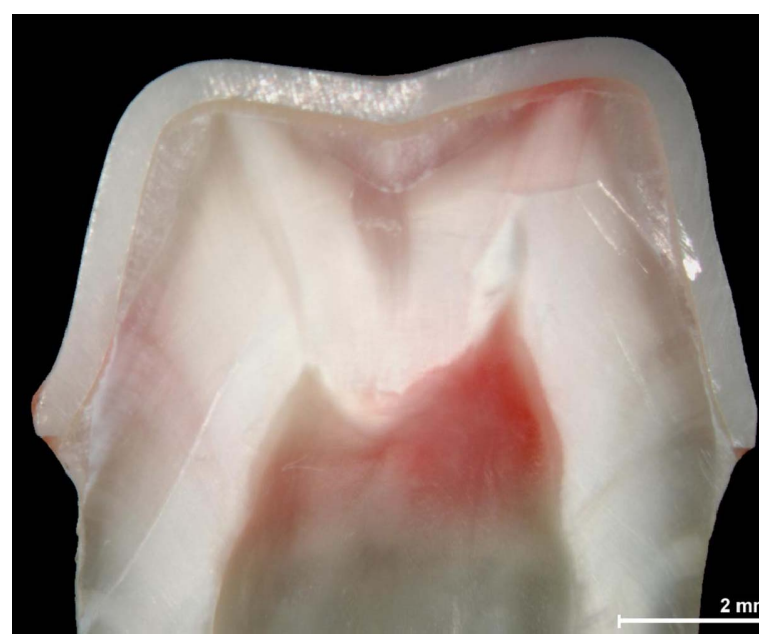

Figure 5. Representative microphotograph of microleakage detection with $2 \%$ fuchsine basic. As described in section "material and methods". The tooth section shows leakage up to three thirds of dentin with compromise of pulp. Bar represents $2 \mathrm{~mm}$.

Table 1. Microleakage of ceramic-copings fabricated by CAD/ CAM system Procera, KaVo Everest and Cerec inLab.

\begin{tabular}{ccccccccc}
\hline Microleakage & Procera & \multicolumn{2}{c}{ KaVo Everest } & \multicolumn{2}{c}{ Cerec inLab } & \multicolumn{2}{c}{ Total } \\
\hline Value & $\mathrm{n}^{\mathrm{o}}$ & $\%$ & $\mathrm{n}^{\mathrm{o}}$ & $\%$ & $\mathrm{n}^{\mathrm{o}}$ & $\%$ & $\mathrm{n}^{\mathrm{o}}$ & $\%$ \\
\hline 0 & 3 & 15 & 10 & 50 & 1 & 5 & 14 & 23 \\
1 & 13 & 65 & 5 & 25 & 10 & 50 & 28 & 47 \\
2 & 0 & 0 & 1 & 5 & 1 & 5 & 2 & 3 \\
3 & 1 & 5 & 0 & 0 & 1 & 5 & 2 & 3 \\
4 & 3 & 15 & 4 & 20 & 7 & 35 & 14 & 23 \\
Total & 20 & 100 & 20 & 100 & 20 & 100 & 60 & 100 \\
\hline
\end{tabular}

Table 2. Mean values and SD of marginal discrepancy ( $\mu \mathrm{m})$ of ceramic-copings fabricated by CAD/CAM system Procera, $\mathrm{KaVo}$ Everest and Cerec inLab.

\begin{tabular}{cccccc}
\hline CAD/CAM & n & Mean & SD & Minimun & Maximun \\
\hline Procera & 10 & 62.48 & 8.98 & 48.38 & 72.91 \\
KaVo Everest & 10 & 65.54 & 18.56 & 46.46 & 100.49 \\
Cerec inLab & 10 & 132.18 & 27.75 & 105.07 & 177.90 \\
\hline
\end{tabular}

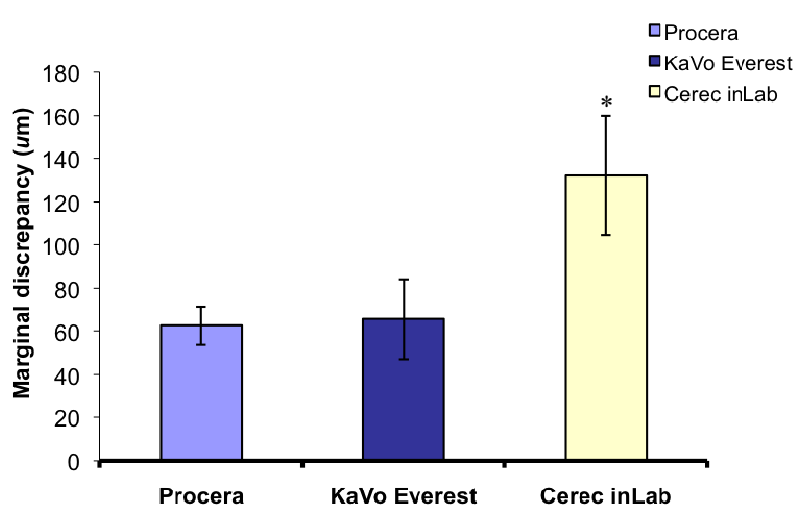

Figure 6. Marginal discrepancy evaluated by Scanning Electron Microscope for each crown ceramic-coping fabricated by $\mathrm{CAD} / \mathrm{CAM}$ system. Results are expressed $(\mu \mathrm{m})$ as mean of 50 measures \pm SD. As described in "material and methods" section. $(P=0.0001$, Kolmogov-Smirnov test, for Procera and KaVo Everest compared to Cerec inLab).

inLab CAD/CAM crown-copings $(P=0.0001$, Kolmogov-Smirnov test) (Figure 6).

The Spearman analysis was use to analyze possible correlations between marginal discrepancy and microleakage for Procera $\mathrm{CAD} / \mathrm{CAM}$ crown-copings $(P=$ $\left.0.803, \mathrm{r}=0.0059, \mathrm{r}^{2}=0.0035\right), \mathrm{KaVo}$ Everest $\mathrm{CAD} /$ CAM crown-copings $\left(P=0.410, r=-0.195, r^{2}=0.038\right)$ and Cerec inLab CAD/CAM crown-copings $(P=0.076$, $\left.r=-0.405, r^{2}=0.016\right)$. The Spearman Rho coefficient determined that there was no correlation between marginal discrepancy and microleakage in any of the three CAD/CAM systems studied.

\section{DISCUSSION}

Several studies under different conditions have highlighted the importance of small marginal discrepancy and a smaller degree of microleakage at the crown-cement interface. The restorations are placed in contact with bacterial enzymes present in saliva and exposed to repeated mechanical loads with intra-oral temperature changes that induce dimensional alteration on the dental materials. It is also known that poor marginal adaptation in crowns increases plaque retention with potential recurrent caries, which often results in restoration failure $[6,12,13]$.

The present in vitro study focused on the differences in microleakage and marginal discrepancies by comparing 
ceramic crown-copings fabricated by three CAD/ CAM systems and cemented with a dual-cured resin Panavia $\mathrm{F}$ 2 .

There is no collectively accepted method used to determine the microleakage patterns of restorative material. Dyes, isotopes, lipopolysaccharides or cell wall materials have all been used [7,8,10-12,16]. Crim et al. [25] reported that a microleakage tests conducted with dyes are not clinically relevant, even though dyes are one of the most common methods used to detect leakage under safe conditions $[8,10-12,16]$.

The present study showed that the degree of dye penetration was zero in $5 \%, 15 \%$ and $50 \%$ of the samples fabricated by Cerec inLab, Procera and KaVo Everest CAD/CAM crown-copings, respectively. Albert et al. [10] reported no microleakage scores in $34 \%$ of Procera AllCeram cemented with resin cement. This data also revealed that significant statistical differences were found for $2 \%$ basic fuchsine solution microleakage in Cerec inLab CAD/CAM ceramic crown-copings when compared with the Procera and KaVoEverest systems. However, there were no significant differences when Procera CAD/CAM crown-copings were compared to the KaVoEverest system. This data is in agreement with similar findings reported by Albert et al. [10] for Procera AllCeram crowns. This observation confirms the findings found in other researches $[8,9,11]$. To the author's knowledge, no published studies on the microleakage in either KaVo Everest or Cerec inLab CAD/CAM crowncopings are available in the English literature.

Zinc phosphate cement has been reported to have higher margin microleakage scores when compared to other luting agents $[8,10,11]$. Several studies have also demonstrated that resin cement results in considerably less microleakage [9-12,26,27]. In the present study, the degree of dye penetration was not influenced by the cement type because all the copings were air-abraded particles with $50 \mu \mathrm{m}$ aluminum oxide and cemented with a dual-cured resin for the three CAD/CAM systems studied. However, Cerec inLab CAD/CAM crown-copings demonstrated the highest leakage.

Various and diverse technologies have been used to evaluate marginal discrepancy both in vitro and in vivo. These studies generally report contradictory results $[2,3$, $5,8,10,11,17-21,26]$. On the one hand, marginal discrepancy in the crowns is evaluated in relation to several factors, including measurements of cemented and noncemented crowns, finish line designs, luting agents, microscope type, laser videography, location and quantity of measurement points, etc. These differences are a constant source of confusion when reporting and comparing studies $[2,3,17,20,21]$.

In the present in vitro study, the highest marginal discrepancy median values for all test groups was found in
Cerec inLab CAD/CAM crown-copings: $132 \pm 27.75 \mu \mathrm{m}$. The marginal discrepancies obtained in this study were greater than the values obtained in by other authors $[3,18,19]$. In a recent study, Bindl et al. [3] reported that the marginal gaps found in Cerec inLab CAD/CAM crowns were $43 \pm 23 \mu \mathrm{m}$. Similar results in gap width were revealed by Nakamura et al. [18] who reported 44 $63 \mu \mathrm{m}$. Rinke et al. [19] found marginal discrepancies between $38 \mu \mathrm{m}$ in non-cemented anterior crowns.

Marginal discrepancies of Procera CAD/CAM crowncopings $(62.5 \pm 8.98 \mu \mathrm{m})$ and $\mathrm{KaVo}$ Everest $(65.5 \pm$ $18.56 \mu \mathrm{m})$ presented closer values. Thus, the marginal discrepancy median values of Procera and KaVo Everest CAD/CAM crown-copings found in this study are within the acceptable limits when using the criterion of $120 \mu \mathrm{m}$ as the maximum clinically acceptable marginal opening as reported by Mc Lean and Von Fraunhofer [16]. In vitro results reported marginal discrepancies for Procera all-ceramic restorations ranging from $17 \pm 16 \mu \mathrm{m}$ to $63 \pm$ $13 \mu \mathrm{m}[3,10,17,20]$. The marginal discrepancy values reported in this study for Procera CAD/CAM crown-copings were in agreement with those reported in a previous study of Procera AllCeram crowns with values ranging from $63 \pm 13 \mu \mathrm{m}$ in molars to $56.0 \pm 13 \mu \mathrm{m}$ in premolars [17]. Marginal discrepancy for Procera CAD/CAM crown-copings with a width of $17.18 \pm 8.16 \mu \mathrm{m}$ was reported by Bindl et al. [3] who assumed that a large internal gap width may have favored the small marginal gap dimensions. Others researchers found marginal discrepancies between $32 \mu \mathrm{m}$ to $145 \mu \mathrm{m}$ in posterior in vivo Procera all-ceramic crowns [2,5,22].

The mean marginal discrepancies of $\mathrm{KaVo}$ Everest CAD/CAM crown-copings obtained in the current study are even greater than those reported by Okutan et al.[21] in molar Everest ceramic crowns' marginal fit with values of $33.0 \pm 6.7 \mu \mathrm{m}$ and $46.6 \pm 7.7 \mu \mathrm{m}$ before and after cementation, respectively. Several studies demonstrated that the marginal discrepancy was significantly higher after cementation $[8,21]$.

For this study with chamfer preparations, no signifycant differences were found in marginal discrepancies when comparing Procera CAD/CAM crown-copings to KaVo Everest. Nevertheless, significant differences were determined for Cerec inLab when compared with Procera and KaVo Everest CAD/CAM crown-copings. The differences between the systems can be attributed to the copings fabrication, which could be related with technique sensitivity and the number of steps involved in the coping fabrication.

The differences observed between our results and those reported in the literature could be because the crown-copings were not cemented in the reported cases. As a result, the measurement did not consider the space occupied by the cement, which can be in the range of 20 
$\mu \mathrm{m}$ to $30 \mu \mathrm{m}$ [28]. Additionally, the measurements were only performed at a few points, such as in the case of four measurements per surface $[3,15,20]$. Furthermore, if these measurements were made using an optical microscope, the measurement is less exact than obtained with a SEM as used in this study.

Another important aspect related with the adjustment measurement is the standard deviation (SD) of the mean. The SD is the degree of variability and it is reported as approximately $\pm 20 \mu \mathrm{m}$ in many studies. In some studies, an increase in SD can result in non-uniform distortions of the sub-structure during porcelain cooking cycles, asymmetrical edges of the crown's margin, damage to the crown's margin during fabrication, and incomplete setting during the model's restoration [29]. In the present study, the SD in the Procera and KaVo Everest systems is \pm 8.98 and \pm 18.56 , respectively. In contrast, the Cerec inLab system has a standard deviation of \pm 27.75 , which could indicate that these copings were distorted when being prepared to compensate for the technique used to fabricate these copings.

In this in vitro study, no correlation between marginal discrepancy and microleakage was found for any of the three CAD/CAM systems studied. Similar results have been reported for Procera AllCeram crowns $[8,10]$ and with cast crowns [11].

The first hypothesis that there is no significant difference between the mean marginal discrepancy and microleakage was confirmed for both Procera and KaVo Everest $\mathrm{CAD} / \mathrm{CAM}$ crown-coping cases, whereas for Cerec inLab CAD/CAM crown-copings it was rejected. On the other hand, the second hypothesis, whether there is no correlation between marginal discrepancy and microleakage, was confirmed.

Further research should be performed in order to develop an experimental design to measure the internal fit of copings fabricated by $\mathrm{CAD} / \mathrm{CAM}$ systems in an attempt to analyze how the internal fit modifies marginal discrepancy. Additionally, other causal agents of microleakage should be studied in order to develop adequate measures to prevent it.

\section{CONCLUSIONS}

Within the limitations of this in vitro study, the following conclusions were drawn:

1) Cerec inLab $C A D / C A M$ crown-copings showed significantly higher values for microleakage and marginal discrepancy in comparison with Procera and $\mathrm{KaVo} \mathrm{Ev-}$ erest CAD/CAM crown-copings;

2) No significant differences were observed in microleakage when Procera CAD/CAM crown-copings were compared to KaVo Everest CAD/CAM crown-copings;

3) No significant differences in marginal discrepancies were found between Procera and $\mathrm{KaVo}$ Everest $\mathrm{CAD} /$
CAM crown-copings;

4) An association between marginal discrepancy and microleakage was not observed.

\section{ACKNOWLEDGEMENTS}

This study was supported by University of Concepción Research Foundation, grant DIUC -1.205.102.009-1.0. We also would like to thank Mr. German Osorio, Department of Cell Biology, College of Biological Sciences, University of Concepción, for his assistance with microphotographs.

\section{REFERENCES}

[1] McLean, J.W. (2001) Evolution of dental ceramics in the twentieth century. Journal of Prosthetic Dentistry, 85, 61-66. doi:10.1067/mpr.2001.112545

[2] Kokubo, Y., Ohkubo, C., Tsumita, M., Miyashita, A., Vult Von Steyern, P. and Fukushima, S. (2005) Clinical marginal and internal gaps of Procera All Ceram crowns. Journal of Oral Rehabilitation, 32, 526-530. doi:10.1111/j.1365-2842.2005.01458.x

[3] Bindl, A. and Mörmann, W.H. (2005) Marginal and internal fit of all-ceramic CAD/CAM crown-copings on chamfer preparations. Journal of Oral Rehabilitation, 32, 441-447. doi:10.1111/j.1365-2842.2005.01446.x

[4] Strub, J.R., Rekow, D. and Witkowski, S. (2006) Computer-aided design and fabrication of dental restorations. Current systems and future possibilities. The Journal of the American Dental Association, 137, 1289-1296.

[5] Naert, I., Van Der Donck, A. and Beckers, L. (2005) Precision of fit and clinical evaluation of all-ceramic full restorations followed between 0.5 and 5 years. Journal of Oral Rehabilitation, 32, 51-57. doi:10.1111/j.1365-2842.2004.01374.x

[6] Going, R.E. and Sawinski, V.J. (1966) Microleakage of a new restorative material. The Journal of the American Dental Association, 73, 107-115.

[7] Gwinnett, J.A., Tay, F.R., Pang K.M. and Wei, S.H.Y. (1995) Comparison of three methods of critical evaluation of microleakage along restorative interfaces. The Journal of Prosthetic Dentistry, 74, 575-585. doi:10.1016/S0022-3913(05)80308-7

[8] White, S.N., Ingles, S. and Kipnis, V. (1994) Influence of marginal opening on microleakage of cemented artificial crowns. The Journal of Prosthetic Dentistry, 71, 257-264. doi:10.1016/0022-3913(94)90464-2

[9] Gu, X.-H. and Kern, M. (2003) Marginal discrepancies and leakage of all-ceramic crowns: Influence of luting agents and aging conditions. The International Journal of Prosthodontics, 16, 109-116.

[10] Albert, F.E. and El-Mowafy, O.M. (2004) Marginal adaptation and microleakage of Procera AllCeram crowns with four cements. The International Journal of Prosthodontics, 17, 529-535.

[11] Piwowarczyk, A., Lauer, H.C. and Sorensen, J.A. (2005) Microleakage of various cementing agents for full cast 
crowns. Dental Materials, 21, 445-453. doi:10.1016/j.dental.2004.07.009

[12] Gerdolle, D.A., Mortier, E., Loos-Ayav, C., Jacquot, B. and Panighi, M. (2005) In vitro evaluation of microleakage of indirect composite inlays cemented with four luting agents. The Journal of Prosthetic Dentistry, 93, 563-570. doi:10.1016/j.prosdent.2005.04.004

[13] Jacobs, M.S. and Windeler, A.S. (1991) An investigation of dental luting cement solubility as a function of the marginal gap. The Journal of Prosthetic Dentistry, 65, 436-442. doi:10.1016/0022-3913(91)90239-S

[14] Mjör, I.A., Moorhead, J.E. and Dahl, J.E. (2000) Reasons for replacement of restorations in permanent teeth in general dental practice. International Dental Journal, 50, 362-366.

[15] Holmes, J.R., Bayne, S.C., Holland, G.A. and Sulik, W.D. (1989) Considerations in measurement of marginal fit. The Journal of Prosthetic Dentistry, 62, 405-408. doi:10.1016/0022-3913(89)90170-4

[16] McLean, J.W. and Von Fraunhofer, J.A. (1971) The estimation of cement film thickness by an in vivo technique. British Dental Journal, 131, 107-111. doi:10.1038/sj.bdj.4802708

[17] May, K.B., Russell, M.M., Razzoog, M.E. and Lang, B.R. (1998) Precision of fit: The Procera AllCeram crown. The Journal of Prosthetic Dentistry, 80, 394-404. doi:10.1016/S0022-3913(98)70002-2

[18] Nakamura, T. Nonaka, M. and Maruyamam, T. (2000) In vitro fitting accuracy of copy-milled alumina cores and all-ceramic crowns. The International Journal of Prosthodontics, 13, 189-193.

[19] Rinke, S., Huls, A. and Jahn, L. (1995) Marginal accuracy and fracture strength of conventional and copymilled all-ceramic crowns. The International Journal of Prosthodontics, 8, 303-310.

[20] Suárez, M.J., González de Villaumbrosia, P., Pradíes, G. and Lozano, J.F. (2003) Comparison of the marginal fit of Procera AllCeram crowns with two finish lines. The International Journal of Prosthodontics, 16, 229-232.

[21] Okutan, M., Heydecke, G., Butz, F. and Strub, J.R. (2006)
Fracture load and marginal fit of shrinkage-free $\mathrm{ZrSiO}_{4}$ all-ceramic crowns after chewing simulation. Journal of Oral Rehabilitation, 33, 827-832. doi:10.1111/j.1365-2842.2006.01637.x

[22] Boening, K.W., Wolf, B.H., Schmidt, A.E., Kästner, K. and Walter, M.H. (2000) Clinical fit of Procera AllCeram crowns. The Journal of Prosthetic Dentistry, 84, 419-424. doi: $10.1067 / \mathrm{mpr} .2000 .109125$

[23] Ernst, C.-P., Canbek, K., Eulert, T. and Willershausen, B. (2004) In vivo validation of the historical in vitro thermocycling temperature range for dental materials testing. Clinical Oral Investigations, 8, 130-138. doi:10.1007/s00784-004-0267-2

[24] Groten, M., Axmann, D., Pröbster, L. and Weber, H. (2000) Determination of the minimum number of marginal gap measurements required for practical in vitro testing. Journal of Prosthetic Dentistry, 83, 40-49. doi:10.1016/S0022-3913(00)70087-4

[25] Crim, G.A. and García-Godoy, F. (1987) Microleakage: The effect of storage and cycling duration. The Journal of Prosthetic Dentistry, 57, 574-576. doi:10.1016/0022-3913(87)90339-8

[26] Blatz, M., Sadan, A., Arch, G. and Lang, B.R. (2003) In vitro evaluation of long-term bonding of Procera AllCeram alumina restorations with a modified resin luting agent. The Journal of Prosthetic Dentistry, 89, 381-387. doi:10.1067/mpr.2003.89

[27] Beschnidt, S.M. and Strub, J.R. (1999) Evaluation of the marginal accuracy of different all-ceramic crown systems after simulation in artificial mouth. Journal of Oral Rehabilitation, 26, 582-593. doi:10.1046/j.1365-2842.1999.00449.x

[28] Nakamura, T., Die, N., Kojima, T. and Wakabayashi, K. (2003) Marginal and internal fit of Cerec 3 CAD/CAM all-ceramic crowns. The International Journal of Prosthodontics, 16, 244-248.

[29] Balkaya, M., Cinar, A. and Pamuk, S. (2005) Influence of firing cycles on the margin distortion of 3 all-ceramic crowns systems. The Journal of Prosthetic Dentistry, 95 346-355. doi:10.1016/j.prosdent.2005.02.003 